\title{
Cutaneous Manifestations Related to COVID-19 Immune Dysregulation in the Pediatric Age Group
}

\author{
Désirée Larenas-Linnemann ${ }^{1,2}$ (D) $\cdot$ Jorge Luna-Pech ${ }^{3}$ (D) Elsy M. Navarrete-Rodríguez ${ }^{4}$ (D) $\cdot$ Noel Rodríguez-Pérez $^{5}$ (I) $\cdot$ \\ Alfredo Arias-Cruz ${ }^{6}$ (D) María Virginia Blandón-Vijil ${ }^{7}$ (D) Blanca E. Del Rio-Navarro ${ }^{4}$ (D) - Alan Estrada-Cardona ${ }^{8}$ (D) \\ Ernesto Onuma-Takane ${ }^{7}$ (D) Cesar Fireth Pozo-Beltrán $^{9}$ (D) Adriana María Valencia-Herrera ${ }^{10}$ (D) \\ Francisco Ignacio Ortiz-Aldana ${ }^{11}$ (D) $\cdot$ Mirna Eréndira Toledo-Bahena ${ }^{10}$ (D)
}

Accepted: 12 November 2020 / Published online: 25 February 2021

(C) The Author(s), under exclusive licence to Springer Science+Business Media, LLC part of Springer Nature 2021

\begin{abstract}
Purpose of Review At the juncture of the COVID-19 pandemic, the world is currently in an early phase of collecting clinical data and reports of its skin manifestations, and its pathophysiology is still highly conjectural. We reviewed cutaneous manifestations associated with COVID-19 in the pediatric age group.

Recent Findings Children infected by SARS-CoV-2 usually develop milder respiratory symptoms, but cutaneous manifestations seem a little more prevalent than in adults. These skin features of infection by the coronavirus can be similar to those produced by other common viruses, but there are also reports of cases with more heterogeneous clinical pictures, which have made their classification difficult. To date, the more frequently reported skin variants featured in pediatric cases are purpuric (pseudochilblain, necrotic-acral ischemia, hemorrhagic macules, and/or cutaneous necrosis), morbilliform/maculopapular, erythema multiforme, urticarial, vesicular, Kawasaki-like, and miscellaneous (highly variable in both frequency and severity). Their pathophysiological mechanism is still elusive and is likely to be the result of the complex involvement of one or more mechanisms, like direct virus-induced skin damage, vasculitis-like reactions, and/or indirect injury as a consequence of a systemic inflammatory reaction.

Summary In this review, we presented and discussed clinical cases as examples of different cutaneous responses reported in some children with SARS-CoV-2 infection, differential diagnosis considerations, and a preliminary conceptual approach to some of their probable associated pathologic mechanisms.
\end{abstract}

Keywords COVID-19, pediatric $\cdot$ SARS-COV-2 $\cdot$ Purpuric lesion $\cdot$ Kawasaki-like $\cdot$ Pseudo-chilblain

This article is part of the Topical Collection on Allergic Skin Diseases

Désirée Larenas-Linnemann

marlar1@prodigy.net.mx

Jorge Luna-Pech

lunapech@hotmail.com

Elsy M. Navarrete-Rodríguez

draenavarrete@gmail.com

Noel Rodríguez-Pérez

dr.noel@alergia.ws

Alfredo Arias-Cruz

aarias45@hotmail.com

María Virginia Blandón-Vijil

virginia94@hotmail.com

Blanca E. Del Rio-Navarro

blancadelrionavarro@gmail.com

\author{
Alan Estrada-Cardona \\ alanec_15@yahoo.com.mx \\ Ernesto Onuma-Takane \\ erneonum@prodigy.net.mx \\ Cesar Fireth Pozo-Beltrán \\ firepo11@hotmail.com \\ Adriana María Valencia-Herrera \\ adrianavalenciaherrera@gmail.com \\ Francisco Ignacio Ortiz-Aldana \\ fioa1404@prodigy.net.mx
}

Mirna Eréndira Toledo-Bahena

mirnatoledo@gmail.com

Extended author information available on the last page of the article 


\section{Introduction}

Since the initial report in December 2019 of the first case of atypical pneumonia in Wuhan, China, caused by the new coronavirus, a variety of clinical manifestations have been reported, ranging from asymptomatic presentations - especially in children - to pulmonary or extrapulmonary symptoms fluctuating in severity. On February 11, 2020, the International Commission for Classification of Virus called this new coronavirus "severe acute respiratory syndrome coronavirus 2" (SARS-CoV-2). On the same day, WHO gave the name "coronavirus disease 2019" (COVID-19) to the disease caused by SARS-CoV-2 (1). COVID-19 quickly disseminated to several regions of China and 197 countries and reached the status of pandemic on March 11, 2020 (2).

COVID-19 was noticed to be more prevalent in adults, and the proportion of confirmed cases in children at the beginning was very low. Reported data on COVID-19 in China showed that children under the age of 18 represented only $2.4 \%$ (1). A systematic review reported in May 2020 that in Italy $1.2 \%$ and in the USA $5 \%$ of the COVID cases were children (3). In Mexico by August 16, 2020, 18,278 (3.5\%) cases had been reported in subjects up to 19 years of age, with a slight predominance of males (56\%); more than $80 \%$ had mild symptomatology, and about a sixth required in-hospital management (4•).

Recalcati first described dermatologic manifestations in 18 of 88 patients (20.4\%) hospitalized with COVID-19, none within the pediatric age group. Skin lesions were present in eight patients at admission, while ten developed them during hospitalization. Cutaneous manifestations were erythematous rash (14 patients), widespread urticaria (three patients), and chickenpox-like vesicles (one patient) (5••). In April of this year, a multicenter study of children admitted to a pediatric intensive care unit in Great Britain with multisystemic inflammatory disease associated with SARS-CoV-2, reported that 44\% presented dermatologic manifestations (rash), superposed on symptoms compatible with Kawasaki disease, toxic shock syndrome, hemophagocytic lymphohistiocytosis, and macrophage activation syndrome; clinical and laboratory studies were compatible with COVID-19 (6).

\section{SARS-CoV-2 Structure}

SARS-CoV-2 belongs to the Coronaviridae family, Coronavirinae subfamily, genus beta, B lineage. Its diameter is $60-140 \mathrm{~nm}$ with spikes of 9-12 $\mathrm{nm}$ and two envelope membrane proteins $\mathrm{M}$ and $\mathrm{E}$. In electromicroscopic imaging, its spikes resemble a solar crown, giving it the name coronavirus. Coronaviruses are single-stranded, positive-sense RNA viruses (7). There exist seven coronavirus species that can affect humans; the 229E, OC43, NL63, and HKU1 genotypes are prevalent and cause common cold symptoms $(8,9)$.

\section{SARS-CoV-2 Invasion}

The first step in any viral infection involves penetration of the viral particles into the cell. In the case of SARS-CoV-2. there are four hypothetic pathways involved. The most important one involves angiotensin-converting enzyme 2 (ACE2) $(10,11)$; see Fig. 1.

Expression of ACE2 occurs in different cells: type-2 pneumocytes, enterocytes, macrophages, tongue, ciliated respiratory epithelium, clear cells, endothelium, proximal renal tubule, adipocytes, keratinocytes, and cells of the epidermis. Its expression increases with age, and it is higher in men (10). The cell distribution of ACE2 is very important, as it helps explain most of the symptoms (e.g., anosmia; taste disturbances; respiratory, cardiovascular, renal, and cutaneous symptoms) we see in patients with COVID 19 and it might contribute to the higher prevalence in men and in adults versus children (11•).

Related to the subject of this review, ACE2 is a membranebound receptor in cells of the basal epidermis and eccrine sweat glands. In normal skin, ACE2 is protected by the stratum corneum, but skin damage could allow the virus to reach its receptor. Eccrine glands are expressed in a large quantity in palms $(12,13)$.

The viral spike protein S of SARS-CoV-2 binds to ACE2 as a cellular receptor, and its affinity is 10-20-fold higher than that of SARS-CoV-1, augmenting its pathogenicity. This binding facilitates the entry of viral RNA assisted by the action of the protease TMPRSS2, which cuts the viral spike exposing subprotein $\mathrm{S} 1$ with the receptor-binding domain (RBD) $(12,14)$ (Fig. 2).

\section{Immune Response to SARS-CoV-2}

Once inside the cell, the genetic material and proteins are recognized by the innate immune system by both transmembrane and intracytoplasmic toll-like receptors (TLR3, TLR7, RIG-1, MDAS) that activate nuclear factors, inducing the production of pro-inflammatory cytokines. However, coronaviruses use different mechanisms to evade the immune system, creating a balance between viral elimination and permanence $(10,11,15,16)$. See Fig. 3.

The skin manifestations in COVID-19 are influenced by the abovementioned conditions. for example, the presence of ACE2 in the skin and the immune responses previously described; however, other mechanisms, like type III hypersensitivity reactions in the vascular endothelium, have also been described (16-18) resembling pathologic mechanisms of autoimmune diseases. In addition, cutaneous manifestations of SARS-CoV-2 infection can be induced by inflammatory cytokines produced by dermal dendritic cells, lymphocytes, mast cells, macrophages, and complement deposition (C5b-9 and C4) on endothelial cells of dermal capillaries $(16,19,20)$. Ultimately, the viral spike has the ability to activate complement, favoring more inflammatory damage $(16,17,19,21)$. 


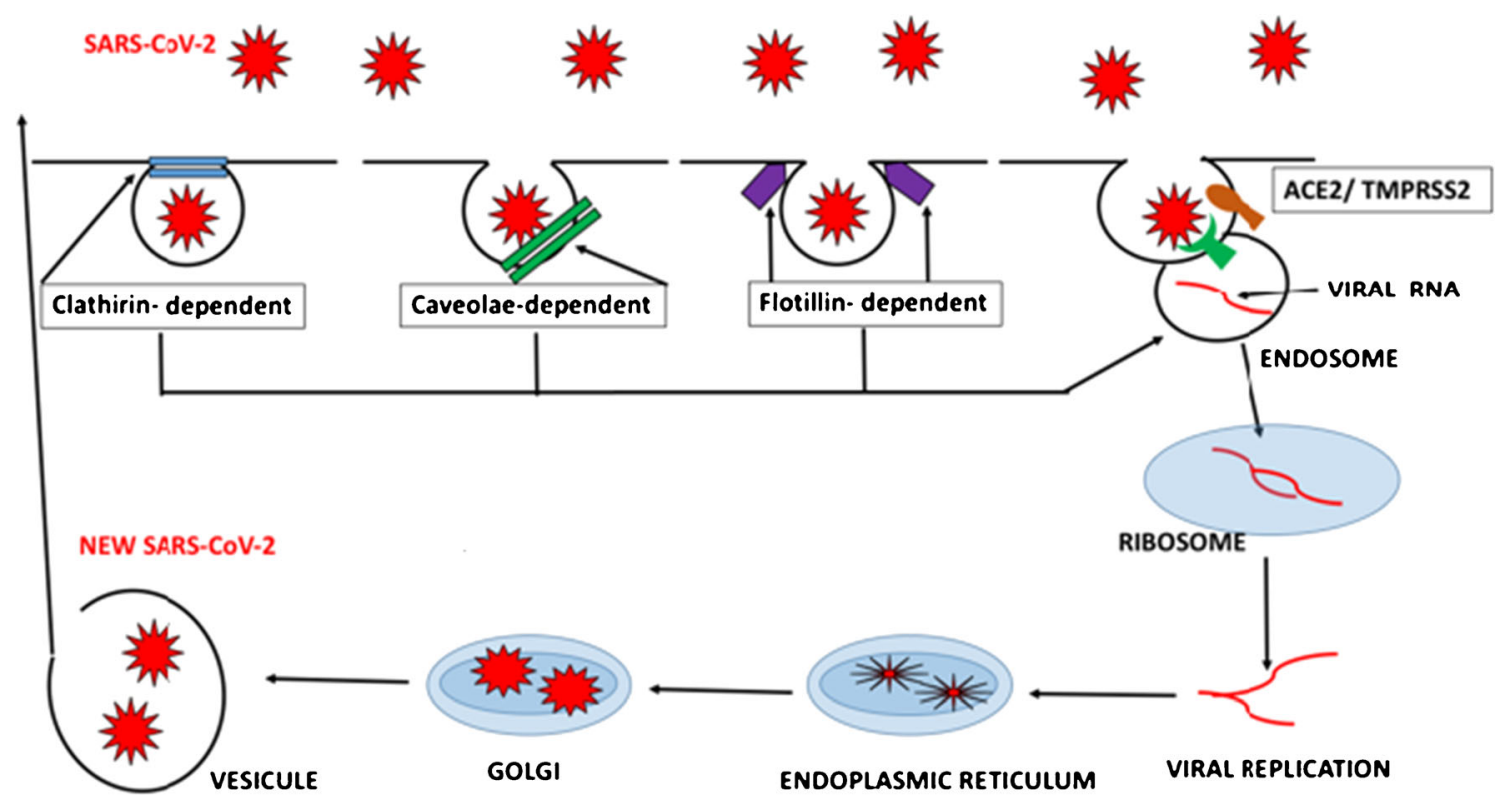

Fig 1 Hypothetic pathways involved in SARS-CoV-2 invasion into the host cell. Clathrin dependent, caveola dependent, flotillin dependent, and ACE2/TMPRSS2 dependent. Once the integrity of the cell membrane has

been broken, viral RNA forms an endosome into the cell's cytoplasm and uses the cellular machinery for viral replication and assembly

The different skin manifestations seen during this pandemic can be classified into 6 "main" categories and one miscellaneous subcategory, adjusted according to our findings in the pediatric age group (17•); see Table 1.

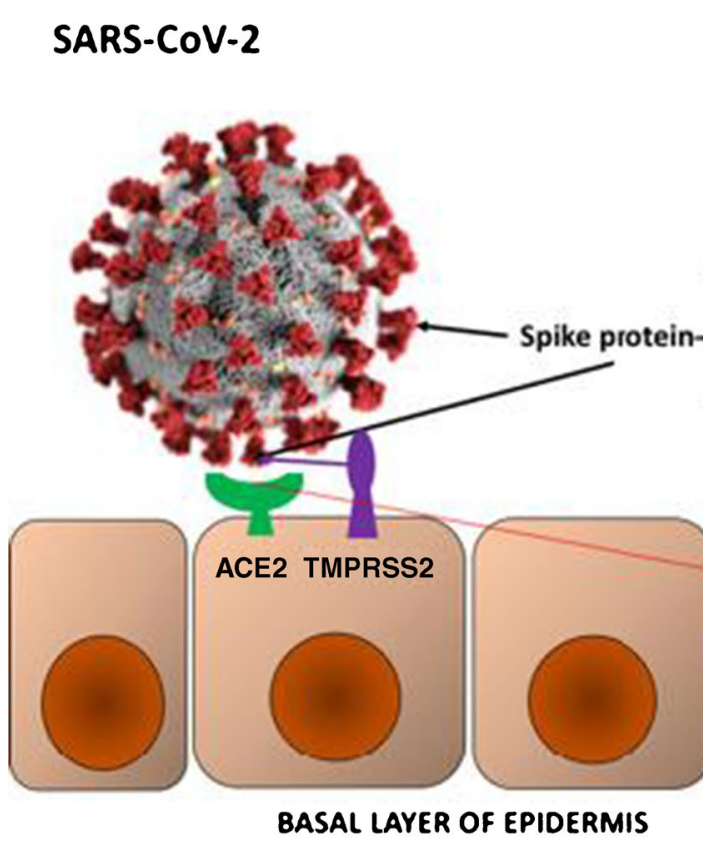

Fig. 2 On the left-hand side, a schematic representation of the SARSCoV-2 virus spike protein bound to the host cell (epidermis) via ACE2 and TMPRSS2. The spike protein contains two subunits, S1 and S2, containing the receptor-binding domain (RBD). The RBD is part of the $\mathrm{S} 1$ subunit, and the $\mathrm{S} 2$ subunit is for membrane fusion. The serine protease TMPRSS2 cleaves the spike glycoprotein between S1 and S2,
Subunit $\mathbf{S 1}$ with RBD Spike protein SARS-CoV-2

Subunit S1

Subunit $\mathbf{2 2}$

ACE2
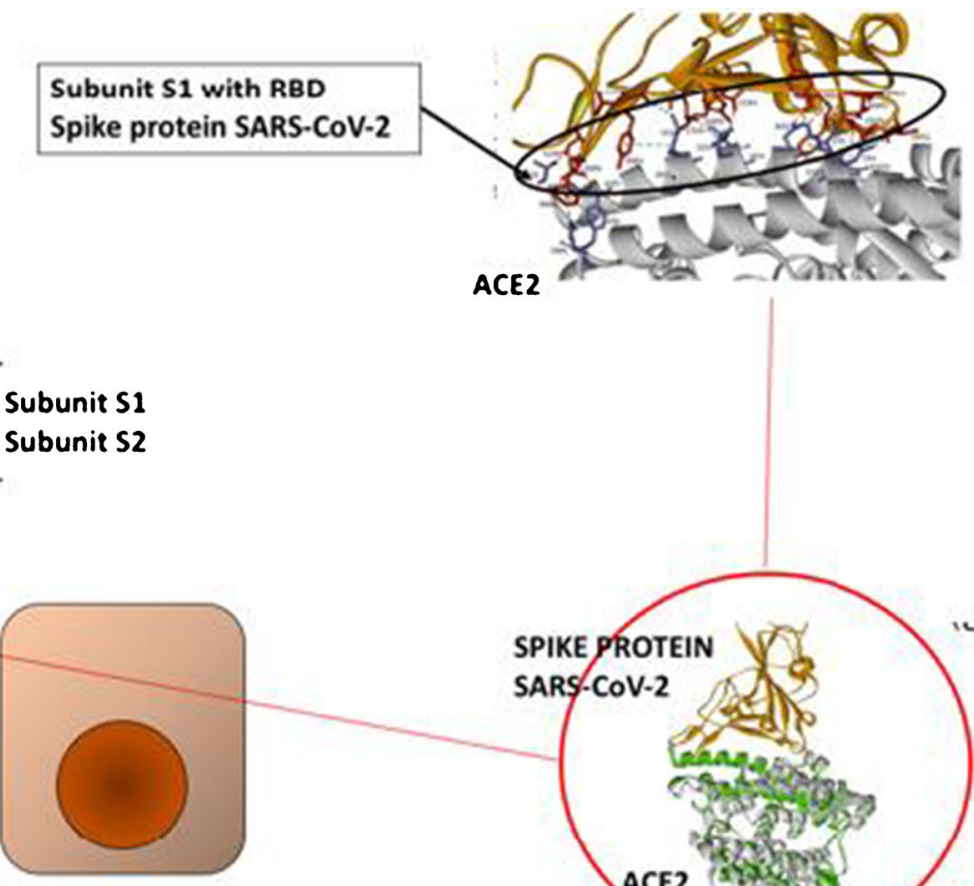

which helps the virus to integrate into the cell membrane and allow it to enter the host cell. At the molecular level, the binding includes amino acids, hydrogens bonds, and electrostatic and hydrophobic interactions. On the right-hand side, crystallographic image of ACE2 and the spike protein and RBD within the $\mathrm{S} 1$ subunit binding to the receptor site of ACE2 


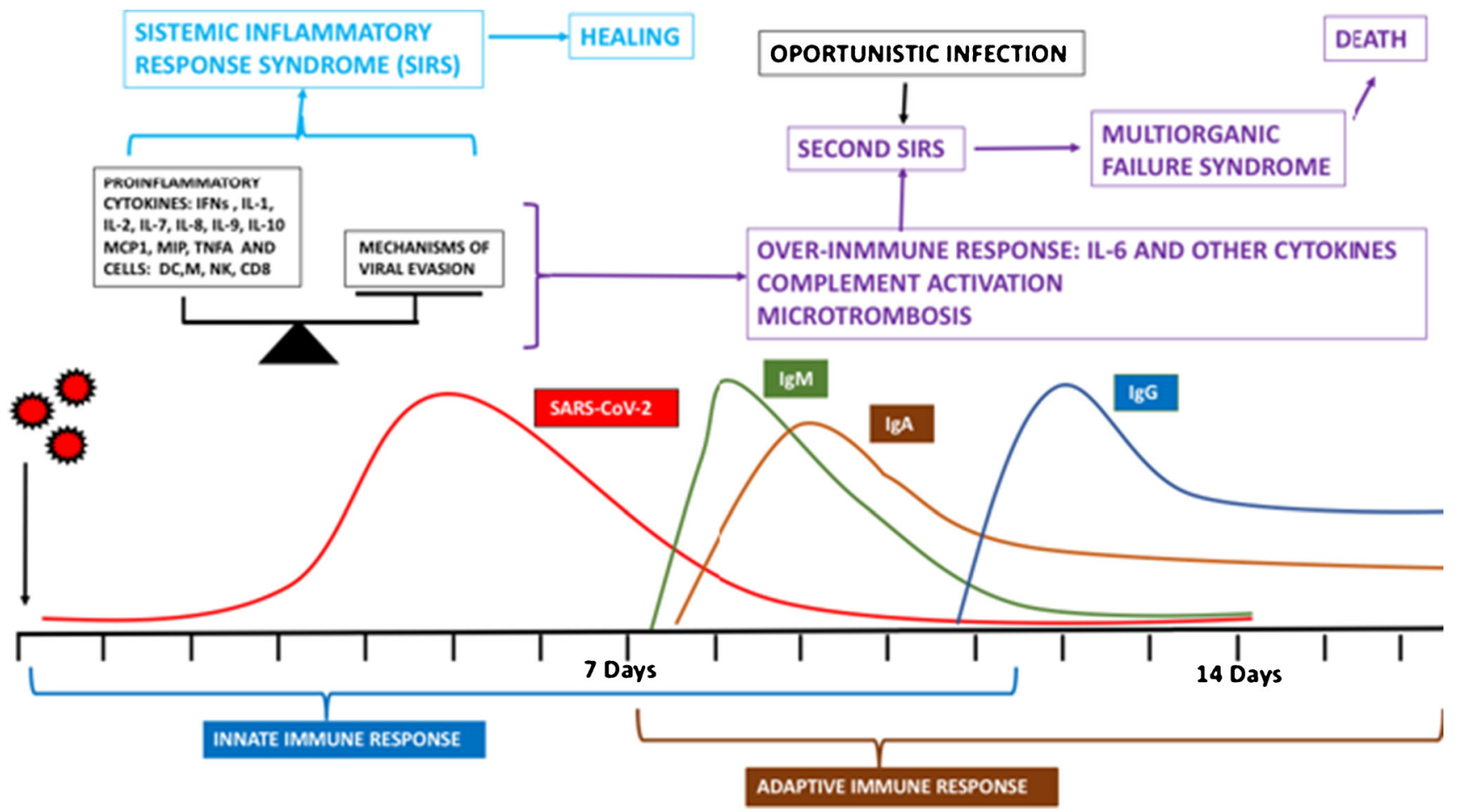

Fig. 3 Immune response to SARS-CoV-2. The first barrier to stop viral spreading comes from the innate immune system. A balance is produced between elimination and survival of the virus. The inflammatory response induced by PAMP sensors, among others TLRs, stimulating the production of pro-inflammatory cytokines, some with chemoattractant properties, is fundamental. As such, natural killer cells (NK), macrophages (M), dendritic cells (DC), CD8 T cells, and cytokines like interferons (IFNs), TNF $\alpha$, monocytic chemoattractant protein 1 (MCP1), and macrophage inflammatory protein (MIP) are part of this first barrier; during this first phase, the virus uses different ways of evasion. The balance between both determines which path shall be followed: the one of viral elimination brought on by a systemic inflammatory response

$M I S-C$ multisystem inflammatory syndrome in children

\section{Methods}

The here presented review shall be divided into two sections. For each of the cutaneous manifestation, we present one of our

Table 1 Skin manifestations in pediatric COVID-19 cases

1. Purpuric lesions

(a) Pseudo-chilblain

(b) Necrotic-acral ischemia, hemorrhagic macules, and cutaneous necrosis

2. Morbilliform or maculopapular

3. Erythema multiforme

4. Urticarial

5. Vesicular

6. Kawasaki-like (typical or atypical; could be associated with MIS-C)

7. Miscellaneous: livedo reticularis, maculopapular-pityriasis, rosea-like, erythema elevatum diutinum, enanthem, flexural rash syndrome (SIRS) ending with healing or the one of virus permanence that subsequently produces an over-activated immune response (the socalled immune hyperactivation, or erroneously referred to as the cytokine storm) advancing into a second SIRS, with activation of complement and the coagulation cascade, which, if not stopped, evolves into a multiorgan failure syndrome and death. An opportunistic infection can appear at this stage, activating SIRS with even more fatal consequences. The adaptive immune response is the second barrier and appears later with a powerful humoral and cellular immune response: IgM is the first antibody to appear followed by IgA and IgG. Specific IgG memory can last up to 3 months or more

cases, followed by a brief review of literature. To this end, we conducted a literature search in PubMed and Embase for original articles and case reports using the following mesh terms: [COVID-19 OR SARS-CoV-2] AND [cutaneous OR Dermatol*] with the age limit $0-18$ years and publication dates January 1, 2020 till August 1, 2020. The language was restricted to English, Spanish, German, and Dutch. We also searched the Net for unindexed case presentations. Data extracted from the reviewed literature per cutaneous manifestation were the number of pediatric cases presented, start of the cutaneous lesion in relation to the start of the disease and relation to the clinical course, COVID-19 severity or laboratory findings, outcome, and biopsy findings (if presented). Detailed literature review tables with found pediatric cases listed one by one (age, clinical symptoms, etc.) can be found in the online repository (Efiles). The cutaneous manifestations shall be presented in order of frequency in the pediatric age group, which differs from the adult cutaneous COVID-19 cases. 


\section{Cutaneous Manifestation 1: Purpuric Lesions, Mostly Acral (Including Pseudo-chilblain and Necrotic)}

\section{Clinical Case}

$A F$ alkaline phosphatase, $A l b$ albumin, $A S T$ aspartate aminotransferase, $A L T$ alanine aminotransferase, ERS erythrocyte sedimentation rate, GGT gamma glutamyl transpeptidase, $P T$ prothrombin time

\section{Review}

One of the first reports of petechial skin lesions related to COVID-19 was in a Thai patient who was originally misdiagnosed as dengue, due to petechia, low platelet count, and general malaise; when respiratory problems appeared, a nasal swab was performed and a positive result of the RT-PCR for SARS-CoV-2 led to the correct diagnosis (22). Till now we have not found a description of such lesions in children with COVID-19.

Contrarily, acral lesions are common in children. They consist of erythematous-violaceous patches or purpuric spots with ill-defined borders (23-25) that are sometimes associated with hyperkeratotic areas (26) and that can evolve to bullae or digital edema (27). They appear in order of frequency in feet, in hands, or in both locations and are associated with a sensation of mild/moderate pain or itching. The different clinical patterns of acral lesions may be associated with other dermatoses and clinical manifestations.

In preliminary reports, the pseudo-chilblains have been prominently discussed, demonstrating that these usually affect young patients, lasting on average about 12 days, appearing at the end of the COVID-19 disease; these have been associated with a less severe illness in terms of hospital admission, pneumonia, admission to intensive care, or mortality. These can cause pain and/or itching in about a third of the cases (28).

In the literature review (see eFile), we found reports of a total of 228 children aged 2 to 17 years with acral lesions associated with the COVID-19 outbreak and without a personal or family history of rheumatological disorders or of similar, prior-onset lesions (with one exception) (29). Systemic manifestations in general were rare, and when they did occur, they preceded skin lesions by up to a month and could be symptoms of mild flu (23), abdominal discomfort (pain and diarrhea) (28), or-generally low-grade-fever $(24 \bullet \bullet)$. Dermoscopy presented with violaceous erythema, dilated capillaries, and areas of ischemia and hyperpigmentation (28), and biopsies, when performed, revealed non-specific changes except for the presence of fibrin clots in some cases $(30,31)$.

The resolution of the lesions occurred spontaneously in most of the patients without treatment within a maximum of 4-5 weeks after the onset of the dermatosis. In some cases, adjuvants such as steroids and topical antibiotics were used with similar outcome $(32,33)$.

In the beginning, the injuries were associated with acral friction dermatosis, due to changes in habits and behavior in the children (26) such as prolonged sessions of games on the floor, similar to the injuries that occur in ballet dancers and other sports with prolonged friction; however, the increase in dermatological consultations for this condition in the framework of the COVID19 pandemic made us rethink the possibility of being a response produced by the virus.

Until now, the causal relationship of these lesions with COVID-19 has not been established and its pathophysiology has yet to be fully elucidated; of the 127 RT-PCR tests and 35 antibody tests for SARS-CoV-2, only 3 were found positive (1 RT-PCR, 1 IgG, 1 IgM). However, the increase in the appearance of these lesions in both children and adults in the framework of the COVID-19 pandemic is very striking and, also considering the fact that the performance of the tests is not completely solid, makes the need for close monitoring of these patients imperative, not ruling out an infectious process that is almost asymptomatic or in a recovery period.

\section{Cutaneous Manifestation 2: Morbilliform or Maculopapular Rash}

\section{Clinical Case}

\section{Review}

In adult series, a morbilliform rash seems to be the most common cutaneous manifestation of COVID-19 patients: an "erythematous rash" was reported in three-quarters of all dermatologic cases of the already referenced Italian series (5*0) and in $47 \%$ of cases in the Spanish series (34). Although exact ages were not specified, all these cases seem to be in adults. Rarely pediatric case reports have been published. The largest series comes from Jordan: 5/61 hospitalized COVID-19-confirmed children presented a rash described as maculopapular and lacey and distributed on the arms, legs, and neck. In all children, COVID-19 was mild (35). Turkish pediatricians 


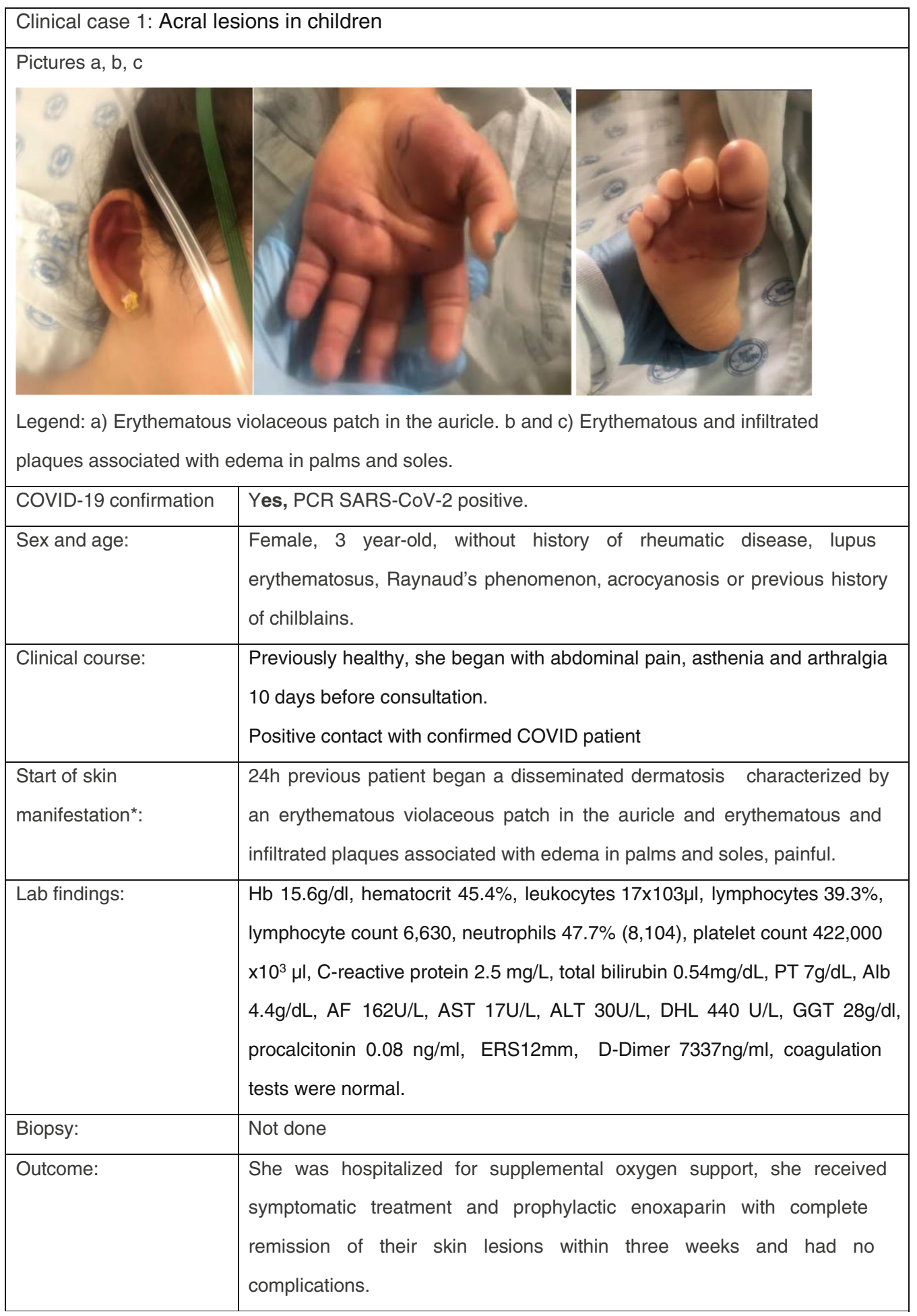


published their experience with twenty hospitalized, COVID-19-confirmed pediatric cases. Three of them developed cutaneous manifestations, one of them probably due to hydroxychloroquine therapy. The second patient, an 11-year-old girl, presented an itchy maculopapular rash on her face and upper trunk on the day of admission, which lasted for 5 days. She was dismissed without further complications. The third patient, an 8-month-old child, presented a roseola-like erythema on her cheeks the day of admission (36•). Klimach et al. in the UK reported on a 13-year-old boy with confirmed COVID-19 whose first clinical presentation was a rash, localized to the plantar aspects of the feet, axillae, and lower limbs. The morphology was predominantly maculopapular, but there were also some petechiae and annular lesions (37•). Finally, Iranian physicians reported a 12-month-old infant presenting with fever and an aggressive maculopapular rash, which turned out to be COVID-19. Fortunately, the child survived the accompanying pneumonia and was discharged after 10 days (38).

\section{Cutaneous Manifestation 3: Erythema Multiforme}

\section{Clinical Case}

\section{Review}

In Spain, a retrospective study of general pediatric dermatology consultations from March 5 to April 15, 2020, reported erythema multiforme (EM)-like patterns in 37/122 (pediatric) patients (28.0\%) aged 129 years (average 12.2 years). These lesions were characterized by rounded erythematous macules and vesicles that tend to coalesce, although compared with classical EM, individual lesions were described as smaller $(<1 \mathrm{~cm}$ diameter $)$ and not usually presented with typical targetoid lesions; also, they were less widespread on $5.4 \%$ of the 37 patients presenting lesions at other sites of the body, including elbows, knees, and ears (39).

In another pediatric dermatology service, Torrelo et al. described in 4 out of 22 (18\%) of COVID-19 cases dual lesions presenting simultaneously EM and chilblains. These lesions were located on the most common cutaneous sites of involvement of classical EM, but the histopathological features were not specific to EM (no necrotic keratinocytes) (40).

A causal link of EM with COVID-19 was supported by the following features: (a) a positive SARS-
CoV-2 PCR test in one patient; (b) a history of contact with a suspected COVID-19 case in one patient and mild respiratory symptoms some days before the skin lesions appeared in three cases; (c) occurrence during the peak period of incidence of COVID-19 in Madrid; (d) the presence of EM and chilblains in the same patients, appearing during an outbreak in an epidemic setting; and (e) the positive immunohistochemistry for SARS-CoV/SARS-CoV-2 spike protein in the endothelia and eccrine epithelia in the two biopsied cases (40).

Bapst et al. also reported a case that presented a multisystem inflammatory syndrome in children and adolescents (MIS-C) temporally related to COVID-19 associated with an erythema multiforme (41). This patient's lesions were isolated round papular on his left shoulder with a central dark red zone surrounded by a pale ring of edema and an erythematous halo on the extreme periphery.

\section{Cutaneous Manifestation 4: Urticaria}

\section{Clinical Case}

\section{Review}

Urticaria is a condition manifested by wheals or hives, angioedema, or both. The hives can be of different shapes and vary in size from less than $5 \mathrm{~mm}$ to more than $10 \mathrm{~cm}$. An evolution of less than 6 weeks is classified as acute urticaria; its prevalence in children varies between 4.5 and $15 \%$. The most common cause of this form of urticaria is infectious, mostly respiratory infections. Other causes include medications and foods (42).

Acute urticaria has been considered a potential manifestation of COVID-19. According to different case reports and analysis of case series that have included children, urticaria could appear as one of the first manifestations of COVID-19, or it could appear at some point during the course of the disease, simultaneously with various signs and symptoms characteristic of COVID-19, with confirmed or strongly suspected SARS-CoV-2 infection. However, of all skin manifestations in children related to COVID-19, urticaria has been one of the least frequently reported ones $(<17 \%)(43-45)$.

The diagnosis of urticaria associated with COVID-19 is basically clinical. The duration of urticaria symptoms is generally short, varying from 6 to 7 days. Nowadays, when acute urticaria appears in a patient associated with fever, the diagnosis of COVID-19 should be considered $(45,46)$.

Other forms of acute urticaria should be considered within the differential diagnosis of urticaria as a sign of COVID-19, including urticaria secondary to the 


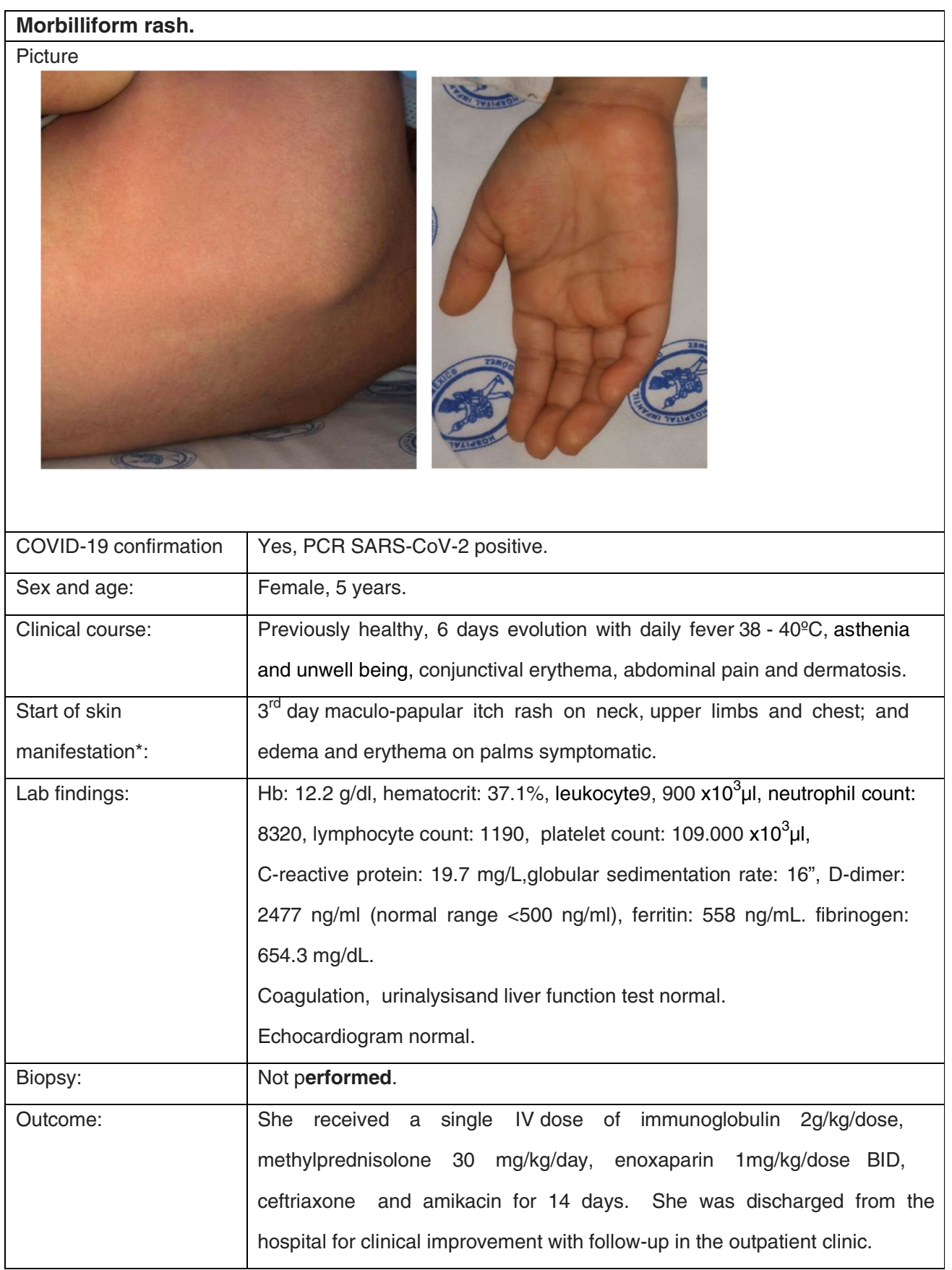

* in relation to the beginning of the first symptoms of COVID-19. 


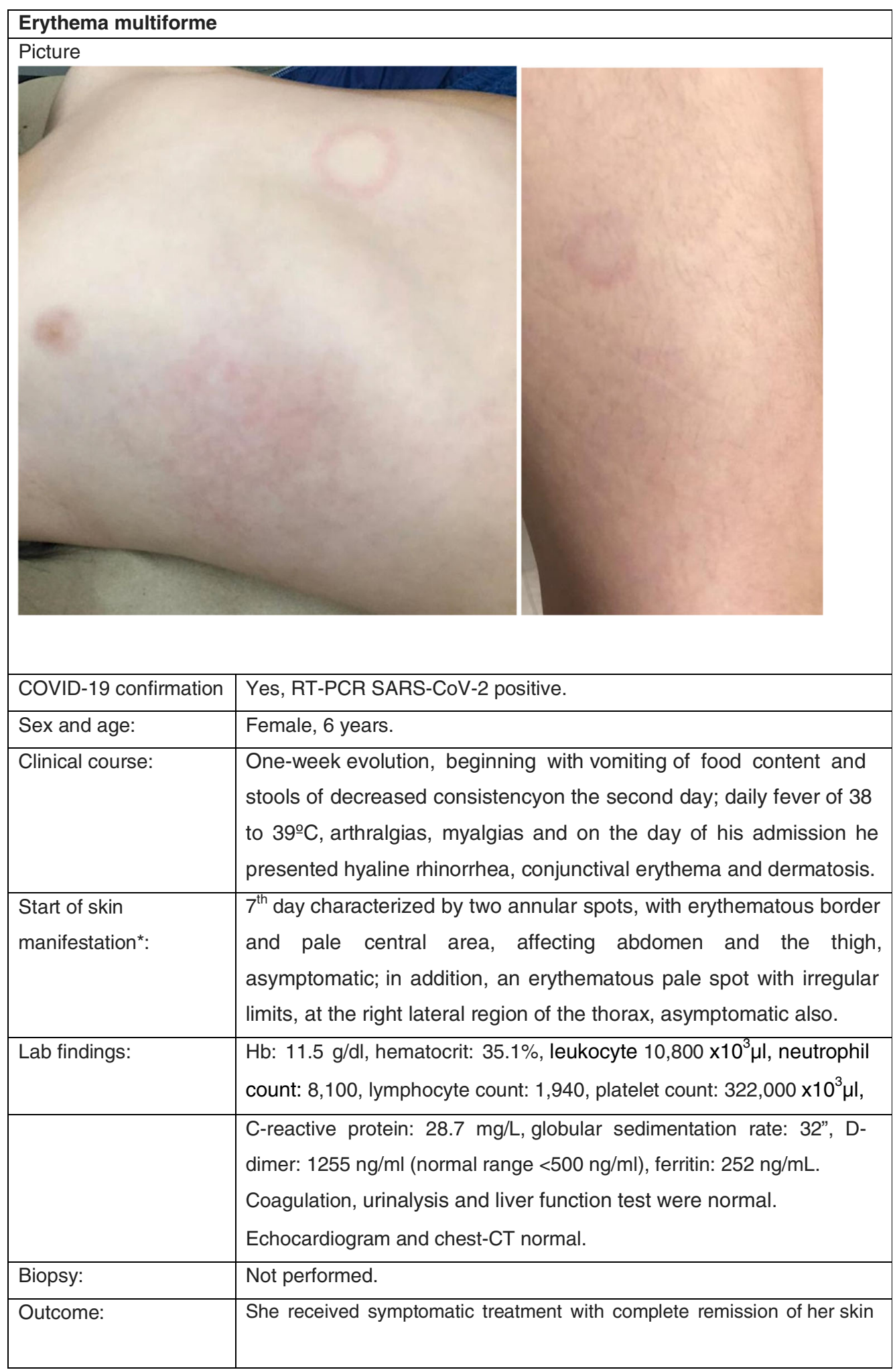

* in relation to the beginning of the first symptoms of COVID-19. 
administration of drugs that can commonly be used in the treatment of patients with COVID-19, such as NSAIDs and antimicrobials (44).

The pathophysiology of urticaria associated with COVID-19 appears to be multifactorial. Proposed mechanisms include direct activation of mast cells by the virus, activation by complement secondary to deposition of antigen-antibody complexes, or mechanisms mediated by bradykinins or IL-6 (46).

The symptomatic treatment of urticaria, including that associated with COVID-19, is based on the administration of second-generation antihistamines, with which patients usually have a good clinical response (42-44).

\section{Cutaneous Manifestation 5: Vesicular}

\section{Clinical Case}

We have no clinical pediatric case with this manifestation. However, we would like to present the diagnostic dilemma we faced in our clinic. A middle-aged male was hospitalized due to respiratory failure secondary to COVID-19, confirmed by RT-PCR. On day 6 , he developed generalized vesicular lesions predominantly on the trunk and fewer on the arms and face; of interest, there was no pruritus, and some ulcerative lesions even caused tenderness with a burning sensation of the area. The patient was managed with a colloidal bath to dry the lesions and deflazacort, responding quickly in 2 days, leaving only residual crusty brown lesions.

Within days, his wife brought us their 5-year-old daughter with a strongly pruritic, papulovesicular rash, and mild flu-like symptoms, frightened it might also be COVID-19. However, the typical varicelliform lesions of the girl, her clinical evolution, and a negative nasal swab finally led to the diagnosis of varicella. A week later, their son also presented a typical case of varicella (courtesy Dr. Rojo-Gutiérrez).

\section{Review}

The first case series published by Italian colleagues of cutaneous manifestations in 18 of 88 hospitalized patients included one case with varicella-like vesicles $(5 \bullet)$. However, all were adults. In a second case series of 22 proven COVID-19 patients with varicelliform lesions and no history of new medications in the previous 15 days, the mean age of the patients was 60 years; but among them, there was one 8 -year-old subject. Here the authors describe that lesions generally started at day 3 and lasted for about a week; strikingly, there was only mild/absent pruritus. Almost all had fever, and 3/22 patients finally died. Skin biopsy, taken in 7 patients, showed histological findings consistent with viral infection (25). Then, there was one case report of an 8-year-old girl with vesicular lesions (47).

Further into the pandemic, Spanish dermatologists published a paper on dermatologic patterns associated with SARS-CoV-2 infection, but without focusing on children. They describe that vesicular eruptions in COVID-19 are especially seen in the third to fourth decade of life in about 9\% of their adult COVID-19 dermatologic cases. As opposed to varicella, the vesicles they described are monomorphic, small in some patients, but large and diffuse in others, filled with hemorrhagic material in some, mainly situated on the trunk. They describe the appearance of the lesions around day 10 of the disease, pruritic in two-thirds and related to an intermediate severity $(48 \bullet \bullet)$.

\section{Cutaneous Manifestation 6: Kawasaki-like and COVID- 19 in ChildrenClinical Case}

\section{Review}

To date, one of the most prominent mucocutaneous feature reported in children with COVID-19 is Kawasaki disease (KD), or more precisely KD-like. KD is a well-known cause of post-infectious vasculitis of medium-sized vessels with persistent fever, mucocutaneous symptoms, and systemic inflammation specifically presenting in the pediatric age group, mainly in small children (0-5-year-olds) (49). Its diagnostic criteria and treatment modalities are described elsewhere $\left(50^{\bullet}\right)$. In the context of the novel pandemic, since the first published case of concurrent COVID-19 and KD in an adolescent (51), several other reports have emerged and special attention has been paid to this supposed clinical concurrence.

Although the pathogenesis of this condition is still unclear, coronavirus-induced disease has been previously reported as one of the known infections that can precede and probably trigger it (52). Given the great increase in worldwide cases of SARS-CoV-2, this fact alone can help to explain the supposed increase in cases of concurrent COVID-19 and KD. Nevertheless, there is still conflicting evidence whether KD is really more prevalent during the SARS-CoV-2 pandemic, firstly as $\mathrm{KD}$ may be underdiagnosed or undergo delayed treatment as a consequence of many parents' hesitation or fear 


\begin{tabular}{|c|c|}
\hline \multicolumn{2}{|l|}{$\begin{array}{l}\text { Urticaria } \\
\text { Picture }\end{array}$} \\
\hline 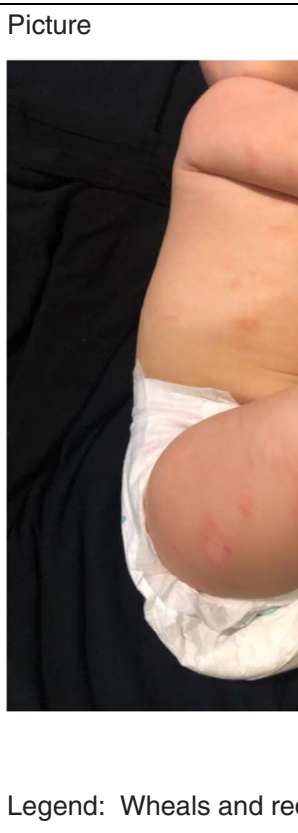 & 2 \\
\hline COVID-19 confirmation & Yes, PCR SARS-CoV-2 positive \\
\hline Sex and age: & Male, 5-month-old \\
\hline Clinical course: & $\begin{array}{l}\text { Previously healthy, } 24 \text { hours of evolution with fever } 38.4^{\circ} \mathrm{C} \text { and dry cough, } \\
\text { azithromycin was indicated. } \\
\text { Positive contact with confirmed COVID patient. }\end{array}$ \\
\hline $\begin{array}{l}\text { Start of skin } \\
\text { manifestation*: }\end{array}$ & $\begin{array}{l}\text { At the same time the patient began adisseminated dermatosis } \\
\text { characterized by wheals and red-raised } \\
\text { blanching rash plaques, azithromycin }\end{array}$ \\
\hline Lab findings: & $\begin{array}{l}\mathrm{Hb} 13 \mathrm{~g} / \mathrm{dl} \text {, hematocrit } 38.5 \text {, leukocyte } 4.7 \times 10^{3} \mu \mathrm{l} \text {, lymphocyte } 75 \% \text {, } \\
\text { lymphocyte count 3,525, neutrophil } 10 \% \text {; neutrophil count } 470 \text {, platelets } \\
171,000 \times 10^{3} \mu \mathrm{l} \text {, C-reactive protein } 2.5 \mathrm{mg} / \mathrm{L} \text {, total bilirubin } 0.4 \mathrm{mg} / \mathrm{dL} \text {, PT } \\
6.2 \mathrm{~g} / \mathrm{dL} \text {, Alb } 4.4 \mathrm{~g} / \mathrm{dL}, \mathrm{FA} 162 \mathrm{U} / \mathrm{L}, \text { AST } 83 \mathrm{U} / \mathrm{L} \text {, ALT } 93 \mathrm{U} / \mathrm{L} \text {, DHL } 440 \mathrm{U} / \mathrm{L} \text {, GGT } \\
28 \mathrm{~g} / \mathrm{dl} \text {, procalcitonin } 0.08 \mathrm{ng} / \mathrm{ml} \text {. }\end{array}$ \\
\hline Biopsy: & Not done \\
\hline Outcome: & $\begin{array}{l}\text { He was treated with paracetamol and antihistamines with improvement of } \\
\text { the symptoms, vigilance in ambulatory clinic. }\end{array}$ \\
\hline
\end{tabular}


to seek in-person consultations for their sick children in these times of sanitary contingency (53). Secondly, because most reported cases come from populations with typical low prevalence of KD (mainly Europe and the USA), while countries with higher KD incidence (i.e., Korea or Japan) have maintained their casuistic relatively stable (54).

More importantly, a high variability of clinical manifestations and outcomes has resulted in conflicting information to adequately categorize KD cases, since many patients have not presented a typical phenotypical picture, and there are increased reports of children with suspected or confirmed COVID-19 and symptoms fulfilling criteria for typical or atypical KD, but frequently associated with unusual age (i.e., older children and adolescents) and/or gastrointestinal symptoms (i.e., diarrhea, ileus); painful limb edema, sometimes overlapping with acute myocarditis associated with toxic shock syndrome and heart failure requiring hemodynamic management; and biochemical evidence of an unusually strong systemic inflammatory response, mostly with features of macrophage activation syndrome with raised serum ferritin.

Due to the almost simultaneous reports (and the lack of a global consensus), a number of semantic and clinical descriptions for apparently the same severe entity related to COVID19 and KD-like symptoms can be found, like "hyperinflammatory shock," "MIS-C," "hyperinflammatory syndrome with multiorgan involvement," "pediatric inflammatory multisystem syndrome (PIMS)," "Kawasaki-like syndrome," or "Kawasaki-like disease" (54). Case definitions are still a work in progress, and although both CDC and the WHO have published similar preliminary diagnostic criteria for suspected cases, they are not completely equivalent, as the CDC criteria are slightly more inclusive, with a broader range of age and a larger list of inflammatory reactants to be considered (Table 2) $(55,56)$.

As far as we can ascertain, two European case series (summarizing 18 patients, mean age 7.5 years) of KD-like clinical features plus shock, high inflammatory indices, and/or acute cardiologic involvement (mainly myocardial) have been published $(57,58)$. In both, despite having a serious clinical picture, most patients did not have severe respiratory symptoms, which is unusual in COVID-19. Most patients fully recovered after intensive management complemented with prompt treatment with intravenous immunoglobulin (a therapeutic modality with strong anti-inflammatory properties approved for both KD and severe acute myocarditis). A much bigger, population-based American study of 186 previously healthy children with MIS-C associated with SARS-CoV-2 infection (mean age 8.3 years) reported similar results. In this study, mucocutaneous features were present in $74 \%$ of the cases $(n$ = 137) (59).
Still, there is high uncertainty over the real concurrency, and thus causal relationship, between KD and COVID-19. Based on the above, there is increasing epidemiologic, clini$\mathrm{cal}$, and laboratory evidence to support the concept of a new hyperinflammatory syndrome separated from KD concurrent with SARS-CoV-2 infection in children. Regardless of the name given to this newly reported condition, the challenge for future studies shall be to understand its pathophysiology, to find consensus to better define its clinical characteristics and biochemical indicators, but mostly to define the best treatment options.

\section{Differential Diagnosis}

A meticulous examination and clinical correlation of dermatologic manifestations and suspected COVID-19 in the pediatric population is needed in order to distinguish similarities between conditions that can be easily misdiagnosed.

In Table 3, we include a summary of diagnosis that need to be taken into account according to the type of dermatological lesion.

\section{Pathophysiology of Cutaneous Lesions in COVID-19}

It seems that COVID-19 can express a plethora of different symptoms and, apart from the respiratory system, can affect other organs including the skin $(17 \bullet)$. As many patients have been treated with medication, before skin lesions appear, it is often impossible to define if the lesions are caused by the infection or due to drug reactions.

The mechanisms by which infection with SARS-CoV-2 could cause skin lesions can fundamentally be divided into three categories:

\section{Vasculitis (69) \\ II. Coagulopathy \\ III. Direct viral infection of skin cells}

These shall be reviewed in more detail below.

\section{COVID-19 and Vasculitis}

It is interesting that the majority of the cutaneous manifestations related to COVID-19 can also be present with different forms of vasculitis (70): mucocutaneous changes commonly related to Kawasaki disease (58); urticaria-like lesions (71); erythematous maculopapular, vesicular, or chickenpox-like rashes (37•); livedo reticularis (72); erythema multiformelike (69); chilblains (73); and petechiae (74). Current 


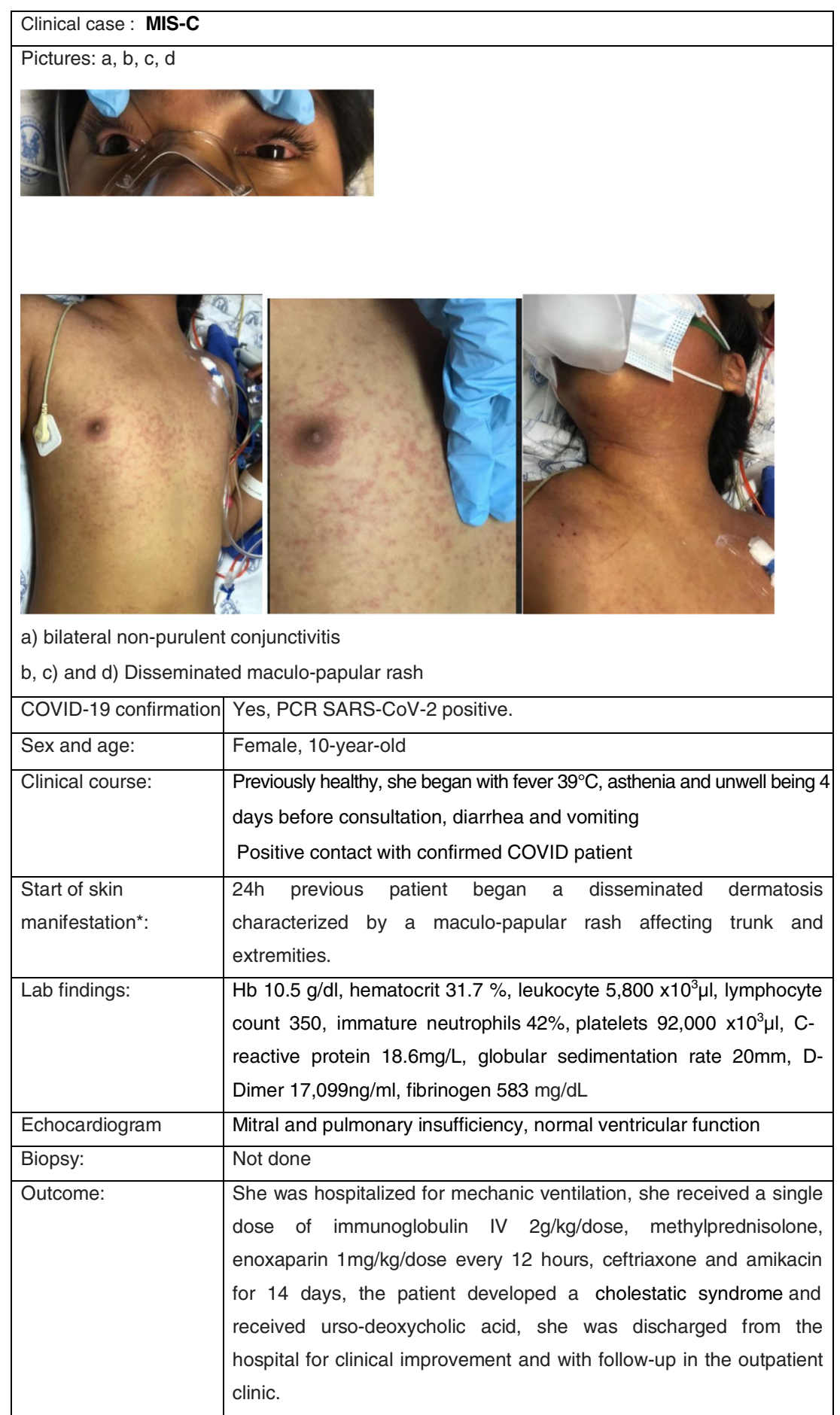


pathophysiological approaches to this disease indicate in fact that vasculitis could be a major pathological mechanism (16).

To date, it is not yet clear if the cutaneous features of the disease are due to direct viral skin affection that cause these changes or if they are secondary complications or a combination of the two (74). Currently, there are not enough solid data to determine the mechanisms by which this coronavirus causes vasculitis, but we can present some speculations, extrapolating observations from other organs. Firstly, it appears that the virus can invade endothelial cells directly (75••), as its receptor, ACE2, is widely present on their surface (76). Biopsy-confirmed endotheliitis has been reported recently in kidney, cardiac, and intestinal tissue, demonstrating the presence of viral elements within endothelial cells and diffuse endothelial inflammation $(75 \bullet \bullet)$.

Secondly, circulating immune complexes can lead to (potentially life-threatening) lymphocytic vasculitis (77). A third probable mechanism by which SARS-CoV-2 can cause skin lesions could be by activation of the keratinocytes through stimulated Langerhans cells, as a consequence of the inflammatory process (78).

\section{Examples of Pathologic Pattern of Cutaneous Lesions} Associated with Vasculitis in Patients with COVID-19 Reports of cutaneous biopsies of COVID-19 positive patients with skin symptoms have taught us that some injury usually takes place within both shallow and deeper skin vessels, inducing lesions commonly seen in vasculitis, like nodules, livedo reticularis, or ulcerations (70). However, there is still great variability in such biopsy findings. For example, tissue reports of a COVID-19-associated exanthematous and hemorrhagic rash showed telangiectatic blood vessels, along with epidermal lymphocytic perivascular infiltrates, Langerhans cell proliferation, and dermal eosinophilic infiltration, while hemorrhagic exanthema lesions showed microthrombi (see below) (78). In another case, an erythema multiforme lesion showed a perivascular and interstitial lymphocyte infiltrate, as well as dermal vasodilation with neutrophils filling and extravasation of red blood cells. Also, this case coexisted with pseudo-vesicles and enanthema, which helped to rule out a drug reaction (69).

Such variability in infiltrates of different cells and pathologic patterns are currently not fully understood, so further microscopic exploration and immuno-histopathologic description of lesions is required to enhance our knowledge about the immunopathologic mechanisms.

The acute urticarial skin lesions described with COVID-19 usually persist for over $24 \mathrm{~h}$ and as such do not fulfill the description of the typical urticaria lesions. They are usually an early feature of the disease (79), but they also may appear in the late phases (80). They do not have the typical histopathological features either (80), and clinically, they behave more like urticarial vasculitis (6).

\section{COVID-19 and Microthrombi}

COVID-19-associated coagulopathy (CAC) refers to a state of hypercoagulability demonstrated not only in several patients, especially in the critically ill, where it resembles disseminated intravascular coagulopathy (DIC), but also in mild cases. This has been related to $(81)$

1. Augmented factor VIII

2. Augmented fibrinogen

3. Circulating prothrombotic microparticles

4. Neutrophil extracellular traps (NETs)

5. Hyperviscosity of plasma

6. Release of the von Willebrand factor by endothelial injury

From cutaneous biopsy and autopsy samples from 3 individuals with severe COVID-19, a pauci-inflammatory, complement-mediated microthrombotic pattern was documented in the skin, with retiform and purpuric lesions and C5b-9 and C4d deposition in samples from both cutaneous lesions and normal-appearing skin (19).

Accordingly, another mechanism of skin damage is related to the formation of microthrombi. These can develop in situ, or there is also a possibility that microthrombi detached from other organs cause a reduced blood perfusion to the microvasculature of the skin (causing the appearance of livedo reticularis) or as a complication from disseminated intravascular coagulation. All these mechanisms can lead to different skin manifestations (72).

\section{Direct Viral Infection of Skin Cells}

Still another proposed etiology for rash in patients with COVID-19 has been direct invasion of cutaneous cells by the virus, based on observed high concentrations of lymphocytes without eosinophils, papillary dermal edema, epidermal spongiosis, and lympho-histiocytic infiltrates (74).

The histopathology of the skin specimens in some COVID19 patients shows the classic dyskeratotic cells and ballooning multinucleated cells and sparse necrotic keratinocytes with lymphocytic satellitosis (78). These overlapping features mimic a viral infection, especially by Herpesviridae.

Histopathological changes at an early stage of an exanthema involving the trunk and limbs showed in the upper dermis diffuse telangiectatic small blood vessels with no other peculiar features; in a second biopsy, nests of Langerhans cells within the epidermis were the unique clue in this stage. 
Table 2 CDC and WHO preliminary case definition criteria for the multisystem inflammatory syndrome (or disorder) in children

Centers for Disease Control and Prevention (CDC) (55••)

An individual aged $<21$ years presenting with fever, ${ }^{\mathrm{i}}$ laboratory evidence of inflammation, ${ }^{\mathrm{ii}}$ and evidence of clinically severe illness requiring hospitalization, with multisystem $(\geq 2)$ organ involvement (cardiac, renal, respiratory, hematologic, gastrointestinal, dermatologic or neurological)

And

No alternative plausible diagnoses

And

Positive for current or recent SARS-CoV-2 infection by RT-PCR, serology, or antigen test or COVID-19 exposure within the 4 weeks prior to the onset of symptoms

World Health Organization (56)

Children and adolescents $0-19$ years of age with fever $\geq 3$ days

And two of the following:

1. Rash or bilateral non-purulent conjunctivitis or mucocutaneous inflammation signs (oral, hands or feet)

2. Hypotension or shock

3. Features of myocardial dysfunction, pericarditis, valvulitis, or coronary abnormalities (including ECHO findings or elevated troponin/NT-proBNP)

4. Evidence of coagulopathy (by PT, PTT, elevated D-dimers)

5. Acute gastrointestinal problems (diarrhea, vomiting, or abdominal pain) And

Elevated markers of inflammation such as ESR, C-reactive protein, or procalcitonin

And

No other obvious microbial cause of inflammation, including bacterial sepsis and staphylococcal or streptococcal shock syndromes

And

Evidence of COVID-19 (RT-PCR, antigen test, or serology positive) or likely contact with patients with COVID-19

${ }^{\mathrm{i}}$ Fever $\geq 38.0^{\circ} \mathrm{C}$ for $\geq 24 \mathrm{~h}$ or report of subjective fever lasting $\geq 24 \mathrm{~h}$

${ }^{i i}$ Including, but not limited to, one or more of the following: an elevated C-reactive protein (CRP), erythrocyte sedimentation rate (ESR), fibrinogen, procalcitonin, D-dimer, ferritin, lactic acid dehydrogenase (LDH), or interleukin 6 (IL-6), elevated neutrophils, reduced lymphocytes, and low albumin

When purpuric maculo-papulo-vesicular rash developed, histological findings showed perivascular spongiotic dermatitis with exocytosis along with a large nest of Langerhans cells and a dense perivascular lymphocytic infiltration, eosinophil rich, around the swollen blood vessels with extravasated erythrocytes (78).

Among skin pathologies in which a virus is implicated, we can see various types of manifestations in the cutaneous area involved. Frequently, it is merely an exanthema indicating a hematogenous spreading of the virus through the cutaneous vascular system. The next step could create activation of the immune system with mobilization of lymphocytes and Langerhans cells patrolling that run through the skin-lymph node path. If the virus swarm induces the creation of immune complexes, this can lead $\mathrm{CD} 4+\mathrm{T}$ helper cells to produce cytokines, like IL-1, IFN- $\gamma$, and TNF- $\alpha$, and to recruit eosinophils, CD8+ cytotoxic T cells, B cells, and natural killer (NK) cells, creating lymphocytic thrombophilic arteritis (82). There are underhanded viral attacks that probably induce a modification in the structure of the keratinocytes that then can be destroyed by cytotoxic lymphocytes, almost resembling the well-known ancient trick of the "Trojan horse"(78).

\section{Conclusion}

In this review, we presented and discussed clinical cases as examples of different cutaneous responses previously reported in some children with SARS-CoV-2 infection, which, to date, are poorly categorized due the high heterogeneity among different case series, in both frequency and severity. As new studies emerge and a better clinical description of these cutaneous symptoms is defined and their causal mechanism is better understood, a clearer framework will be available to properly interpret them for diagnostic, therapeutic, and prognostic purposes. Until then, physicians should be very careful in evaluating skin reactions in children with suspected coronavirus-induced disease and when possible collaborate in enhancing our understanding by publishing them.

\section{Compliance with Ethicals Standards}

Conflict of Interest The authors declare no conflicts of interest relevant to this manuscript.

Human and Animal Rights and Informed Consent This article does not contain any studies with human or animal subjects performed by any of the authors. 
Table 3 Main differential diagnosis according to dermatological lesions (60-68)

Clinical symptoms and signs
Laboratory findings apart from RT- Comments

PCR (-)

\begin{tabular}{cl}
\hline $\begin{array}{l}\text { Morbilliform rash } \\
\text { Measles }\end{array}$ & -Malaise, anorexia, conjunctivitis, coryza, and cough \\
& -Koplik spots \\
& -High-grade fever \\
& -Maculopapular rash that spreads cephalocaudally \\
Roseola infantum & -Edema in eyelids \\
(exanthem subitum) & -Fever that exceed $40{ }^{\circ} \mathrm{C}\left(104{ }^{\circ} \mathrm{F}\right)$ during 3-5 days \\
& resolves followed by rash \\
& -Children are active and well \\
Erythema infectiosum & -Slapped cheeks followed by erythematous \\
& maculopapular rash in arms and trunk with \\
& reticular pattern \\
& -Associated palpebral edema \\
& -Maculopapular rash \\
Dengue/Zika/chikun- & -Scarlet fever-like \\
gunya & -Red and bright petechiae \\
& -Severe arthralgia \\
& -Bullous and vasculitis skin lesions associated with \\
& condition aggravated (chikungunya)
\end{tabular}

Chilblain

Meningococcemia (60) -Critically ill patient

-Sudden onset of skin lesions

-Meningismus and impaired consciousness

\begin{tabular}{|c|c|}
\hline \multirow[t]{4}{*}{ Henoch-Schönlein* } & -Moderate-severe abdominal pain \\
\hline & Hematuria \\
\hline & -Palpable lesions \\
\hline & -Lower extremity distribution \\
\hline Hemorrhagic edema & -Low-grade fever, non-toxic appearance \\
\hline & $\begin{array}{l}\text {-Target-like, macular to purpuric plaques in face, ear } \\
\text { lobes and extremities; non-pitting edema of the } \\
\text { distal extremities }\end{array}$ \\
\hline \multicolumn{2}{|l|}{ Acral } \\
\hline Trauma & -Local trauma history \\
\hline Contact dermatitis & $\begin{array}{l}\text {-Excessive sweating of the feet or exposure to water } \\
\text { and detergents }\end{array}$ \\
\hline Septic emboli & $\begin{array}{l}\text {-Infective endocarditis related, cardiac surgery, or IV } \\
\text { drug abuse }\end{array}$ \\
\hline
\end{tabular}

Erythema multiforme-like

Acute urticaria

Food or drug allergy -Repeated symptoms on re-exposure -No fever

Viral infections

-Systemic symptom according to causal virus

Chickenpox-like rashes Chickenpox
Seldom needed

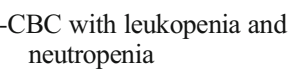

Serologic confirmation and/or PCR despite report of vaccination

$90 \%$ of cases occur in children younger than 2 years of age

Serology confirmation and/or PCR

-Present in endemic areas -RT-PCR/serological testing
-Normal CBC

-Renal involvement

-Not needed

CBC with leukocytosis and neutrophilia 


\section{References}

Papers of particular interest, published recently, have been highlighted as:

- Of importance

- Of major importance

1. She J, Liu L, Liu W. COVID-19 epidemic: disease characteristics in children. J Med Virol. 2020;92(7):747-54.

2. WHO Director-General's opening remarks at the media briefing on COVID-19 - 11 March 2020: World Health Organization; 2020 [Available from: https://www.who.int/dg/speeches/detail/whodirector-general-s-opening-remarks-at-the-media-briefing-oncovid-19\%2D\%2D-11-march-2020.

3. Ludvigsson JF. Children are unlikely to be the main drivers of the COVID-19 pandemic - a systematic review. Acta Paediatr. 2020;109(8):1525-30.

4. DGE. Covid-19 México: CONACYT - CentroGeo - GeoInt DataLab; 2020 [updated August 16th, 2020. Available from: https://coronavirus.gob.mx/datos/. Official database of the Mexican government on health statistics related to COVID19 , sorted by age group.

5.• Recalcati S. Cutaneous manifestations in COVID-19: a first perspective. J Eur Acad Dermatol Venereol. 2020. First publication on dermatologic manifestations related to COVID-19 (all in adults).

6. Davis MDP, van der Hilst JCH. Mimickers of urticaria: urticarial vasculitis and autoinflammatory diseases. J Allergy Clin Immunol Pract. 2018;6(4):1162-70.

7. Lu R, Zhao X, Li J, Niu P, Yang B, Wu H, et al. Genomic characterisation and epidemiology of 2019 novel coronavirus: implications for virus origins and receptor binding. Lancet. 2020;395(10224):565-74.

8. Wiersinga WJ, Rhodes A, Cheng AC, Peacock SJ, Prescott HC. Pathophysiology, transmission, diagnosis, and treatment of coronavirus disease 2019 (COVID-19): a review. JAMA. 2020.

9. Lu X, Xiang Y, Du H, Wing-Kin Wong G. SARS-CoV-2 infection in children - understanding the immune responses and controlling the pandemic. Pediatr Allergy Immunol. 2020. * Comprehensive review of COVID-19 in children, specifically focusing on the immune responses.

10. Glebov OO. Understanding SARS-CoV-2 endocytosis for COVID19 drug repurposing. FEBS J. 2020.

11. Matricardi PM, Dal Negro RW, Nisini R. The first, holistic immunological model of COVID-19: implications for prevention, diagnosis, and public health measures. Pediatr Allergy Immunol. 2020. Very comprehensive review of immunologic changes secondary to SARS-CoV-2 infection, linking them to diagnosis and prevention. No special note on children.

12. Hussain M, Jabeen N, Raza F, Shabbir S, Baig AA, Amanullah A, et al. Structural variations in human ACE2 may influence its binding with SARS-CoV-2 spike protein. J Med Virol. 2020.

13. Muus C, Luecken M, Eraslan G, Waghray A, Heimberg G, Sikkema L, et al. Integrated analyses of single-cell atlases reveal age, gender, and smoking status associations with cell type-specific expression of mediators of SARS-CoV-2 viral entry and highlights inflammatory programs in putative target cells. bioRxiv. 2020: 049254.

14. Bourgonje AR, Abdulle AE, Timens W, Hillebrands JL, Navis GJ, Gordijn SJ, et al. Angiotensin-converting enzyme 2 (ACE2), SARS-CoV-2 and the pathophysiology of coronavirus disease 2019 (COVID-19). J Pathol. 2020.

15. Chang, Zhao P, Zhang D, Dong JH, Xu Z, Yang G, et al. Persistent viral presence determines the clinical course of the disease in COVID-19. J Allergy Clin Immunol Pract. 2020;8(8):2585-91 e1.
16. Criado PR, Abdalla BMZ, de Assis IC. van Blarcum de Graaff Mello C, Caputo GC, Vieira IC. Are the cutaneous manifestations during or due to SARS-CoV-2 infection/COVID-19 frequent or not? Revision of possible pathophysiologic mechanisms. Inflamm Res. 2020;69(8):745-56.

17. Gupta A, Madhavan MV, Sehgal K, Nair N, Mahajan S, Sehrawat TS, et al. Extrapulmonary manifestations of COVID-19. Nat Med. $2020 ; 26(7): 1017-32$. Review of the extrapulmonary organspecific pathophysiology and linking this to the presentations and management considerations in patients with COVID-19.

18. Jose RJ, Williams AE, Chambers RC. Proteinase-activated receptors in fibroproliferative lung disease. Thorax. 2014;69(2):190-2.

19. Magro C, Mulvey JJ, Berlin D, Nuovo G, Salvatore S, Harp J, et al. Complement associated microvascular injury and thrombosis in the pathogenesis of severe COVID-19 infection: a report of five cases. Transl Res. 2020;220:1-13.

20. Criado PR, de Carvalho JF, Ayabe LA, Brandt HR, Romiti R, Maruta CW. Urticaria and dermographism in patients with adultonset Still's disease. Rheumatol Int. 2012;32(8):2551-5.

21. Llamas-Velasco M, Munoz-Hernandez P, Lazaro-Gonzalez J, Reolid-Perez A, Abad-Santamaria B, Fraga J, et al. Thrombotic occlusive vasculopathy in a skin biopsy from a livedoid lesion of a patient with COVID-19. Br J Dermatol. 2020.

22. Joob B, Wiwanitkit V. COVID-19 can present with a rash and be mistaken for dengue. J Am Acad Dermatol. 2020;82(5):e177.

23. Colonna C, Monzani NA, Rocchi A, Gianotti R, Boggio F, Gelmetti C. Chilblain-like lesions in children following suspected COVID-19 infection. Pediatr Dermatol. 2020;37(3):437-40.

24.• Colonna C, Spinelli F, Monzani NA, Ceriotti F, Gelmetti C. Chilblains in children in the time of Covid-19: new evidence with serology assay. Pediatr Dermatol. 2020. Chilblain lesions in children seemingly have no direct relation to COVID-19 infection.

25. Colonna C, Genovese G, Monzani NA, Picca M, Boggio F, Gianotti R, et al. Outbreak of chilblain-like acral lesions in children in the metropolitan area of Milan, Italy, during the COVID-19 pandemic. J Am Acad Dermatol. 2020.

26. Bodak N, Chiaverini C, Barbarot S. COVID-19 lockdown induced acral dermatosis in children. J Eur Acad Dermatol Venereol. 2020.

27. Recalcati S, Barbagallo T, Frasin LA, Prestinari F, Cogliardi A, Provero MC, et al. Acral cutaneous lesions in the time of COVID-19. J Eur Acad Dermatol Venereol. 2020;34(8):e346-e7.

28. Andina D, Noguera-Morel L, Bascuas-Arribas M, Gaitero-Tristan J, Alonso-Cadenas JA, Escalada-Pellitero S, et al. Chilblains in children in the setting of COVID-19 pandemic. Pediatr Dermatol. 2020;37(3):406-11.

29. Garcia-Lara G, Linares-Gonzalez L, Rodenas-Herranz T, RuizVillaverde R. Chilblain-like lesions in pediatrics dermatological outpatients during the COVID-19 outbreak. Dermatol Ther. 2020: e13516.

30. El Hachem M, Diociaiuti A, Concato C, Carsetti R, Carnevale C, Ciofi Degli Atti M, et al. A clinical, histopathological and laboratory study of 19 consecutive Italian paediatric patients with chilblain-like lesions: lights and shadows on the relationship with COVID-19 infection. J Eur Acad Dermatol Venereol. 2020.

31. Roca-Gines J, Torres-Navarro I, Sanchez-Arraez J, Abril-Perez C, Sabalza-Baztan O, Pardo-Granell S, et al. Assessment of acute acral lesions in a case series of children and adolescents during the COVID-19 pandemic. JAMA Dermatol. 2020.

32. Neri I, Virdi A, Corsini I, Guglielmo A, Lazzarotto T, Gabrielli L, et al. Major cluster of paediatric 'true' primary chilblains during the COVID-19 pandemic: a consequence of lifestyle changes due to lockdown. J Eur Acad Dermatol Venereol. 2020.

33. Mastrolonardo M, Romita P, Bonifazi E, Giuffrida R, Lotti T, Foti $\mathrm{C}$, et al. The management of the outbreak of acral skin manifestations in asymptomatic children during COVID-19 era. Dermatol Ther. 2020:e13617. 
34. Catala A, Galvan-Casas C, Carretero-Hernandez G, RodriguezJimenez P, Fernandez-Nieto D, Rodriguez-Villa A, et al. Maculopapular eruptions associated to COVID-19: a subanalysis of the COVID-Piel study. Dermatol Ther. 2020.

35. Kilani MM, Odeh MM, Shalabi M, Al Qassieh R, Al-Tamimi M. Clinical and laboratory characteristics of SARS-CoV2-infected paediatric patients in Jordan: serial RT-PCR testing until discharge. Paediatr Int Child Health. 2020:1-10.

36. Bursal Duramaz B, Yozgat CY, Yozgat Y, Turel O. Appearance of skin rash in pediatric patients with COVID-19: three case presentations. Dermatol Ther. 2020:e13594. Rash can be a presenting sign of COVID-19 in children.

37. Klimach A, Evans J, Stevens J, Creasey N. Rash as a presenting complaint in a child with COVID-19. Pediatr Dermatol. 2020. Rash can be a presenting sign of COVID-19 in children.

38. Navaeifar MR, Poudineh Ghazaghi M, Shahbaznejad L, Rouhanizadeh H, Abutalebi M, Ranjbar Varandi M, et al. Fever with rash is one of the first presentations of COVID-19 in children: a case report. Int Med Case Rep J. 2020;13:335-40.

39. Fernandez-Nieto D, Jimenez-Cauhe J, Suarez-Valle A, MorenoArrones OM, Saceda-Corralo D, Arana-Raja A, et al. Characterization of acute acral skin lesions in nonhospitalized patients: a case series of 132 patients during the COVID-19 outbreak. J Am Acad Dermatol. 2020;83(1):e61-e3.

40. Torrelo A, Andina D, Santonja C, Noguera-Morel L, Bascuas-Arribas $\mathrm{M}$, Gaitero-Tristan J, et al. Erythema multiforme-like lesions in children and COVID-19. Pediatr Dermatol. 2020;37(3):442-6.

41. Bapst T, Romano F, Muller M, Rohr M. Special dermatological presentation of paediatric multisystem inflammatory syndrome related to COVID-19: erythema multiforme. BMJ Case Rep. 2020;13(6).

42. Larenas-Linnemann D, Medina-Avalos MA, Ortega-Martell JA, Beirana-Palencia AM, Rojo-Gutierrez MI, Morales-Sanchez MA, et al. Mexican guidelines on the diagnosis and treatment of urticaria. Rev Alerg Mex. 2014;61(Suppl 2):S118-93.

43. Young S, Fernandez AP. Skin manifestations of COVID-19. Cleve Clin J Med. 2020.

44. Wollina U, Karadag AS, Rowland-Payne C, Chiriac A, Lotti T. Cutaneous signs in COVID-19 patients: a review. Dermatol Ther. 2020:e13549.

45. Sachdeva M, Gianotti R, Shah M, Bradanini L, Tosi D, Veraldi S, et al. Cutaneous manifestations of COVID-19: report of three cases and a review of literature. J Dermatol Sci. 2020;98(2):75-81.

46. Kaushik A, Parsad D, Kumaran MS. Urticaria in the times of COVID-19. Dermatol Ther. 2020:e13817.

47. Genovese G, Colonna C, Marzano AV. Varicella-like exanthem associated with COVID-19 in an 8-year-old girl: a diagnostic clue? Pediatr Dermatol. 2020;37(3):435-6.

48.• Galvan Casas C, Catala A, Carretero Hernandez G, RodriguezJimenez P, Fernandez-Nieto D, Rodriguez-Villa Lario A, et al. Classification of the cutaneous manifestations of COVID-19: a rapid prospective nationwide consensus study in Spain with 375 cases. Br J Dermatol. 2020;183(1):71-7. Consensus report of Spanish dermatologists related to classification of cutaneous manifestations of COVID-19. No special focus on children, though.

49. Xu S, Chen M, Weng J. COVID-19 and Kawasaki disease in children. Pharmacol Res. 2020;159:104951.

50. McCrindle BW, Rowley AH, Newburger JW, Burns JC, Bolger $\mathrm{AF}, \mathrm{Gewitz} \mathrm{M}$, et al. Diagnosis, treatment, and long-term management of Kawasaki disease: a scientific statement for health professionals from the American Heart Association. Circulation. 2017;135(17):e927-e99. Key paper reviewing Kawasaki disease diagnosis and management.

51. Jones VG, Mills M, Suarez D, Hogan CA, Yeh D, Segal JB, et al. COVID-19 and Kawasaki disease: novel virus and novel case. Hosp Pediatr. 2020;10(6):537-40.
52. Gupta-Malhotra M, Rao PS. Current perspectives on Kawasaki disease. Indian J Pediatr. 2005;72(7):621-9.

53. Harahsheh AS, Dahdah N, Newburger JW, Portman MA, Piram M, Tulloh R, et al. Missed or delayed diagnosis of Kawasaki disease during the 2019 novel coronavirus disease (COVID-19) pandemic. J Pediatr 2020;222:261-2.

54. Kone-Paut I, Cimaz R. Is it Kawasaki shock syndrome, Kawasakilike disease or pediatric inflammatory multisystem disease? The importance of semantic in the era of COVID-19 pandemic. RMD Open. 2020;6(2).

55.• (CPR) CfPaR. Emergency preparedness and response: multisystem inflammatory syndrome in children (MIS-C) associated with coronavirus disease 2019 (COVID-19) 2020 [Available from: https:// emergency.cdc.gov/han/2020/han00432.asp. CDC guidance related to MIS-C associated with COVID-19.

56. Organization WH. Multisystem inflammatory syndrome in children and adolescents temporally related to COVID-19. Scientific brief: World Health Organization; 2020. Available from: https://www.who. int/news-room/commentaries/detail/multisystem-inflammatorysyndrome-in-children-and-adolescents-with-covid-19

57. Riphagen S, Gomez X, Gonzalez-Martinez C, Wilkinson N, Theocharis P. Hyperinflammatory shock in children during COVID-19 pandemic. Lancet. 2020;395(10237):1607-8. One of the first reports of MIS-C in children with COVID-19.

58. Verdoni L, Mazza A, Gervasoni A, Martelli L, Ruggeri M, Ciuffreda M, et al. An outbreak of severe Kawasaki-like disease at the Italian epicentre of the SARS-CoV-2 epidemic: an observational cohort study. Lancet. 2020;395(10239):1771-8.

59. Feldstein LR, Rose EB, Horwitz SM, Collins JP, Newhams MM, Son MBF, et al. Multisystem inflammatory syndrome in U.S. children and adolescents. N Engl J Med. 2020;383(4):334- 46.

60. Thompson MJ, Ninis N, Perera R, Mayon-White R, Phillips C, Bailey $\mathrm{L}$, et al. Clinical recognition of meningococcal disease in children and adolescents. Lancet. 2006;367(9508):397-403.

61. Gisondi P, S PI, Bordin C, Alaibac M, Girolomoni G, Naldi L. Cutaneous manifestations of SARS-CoV-2 infection: a clinical update. J Eur Acad Dermatol Venereol. 2020.

62. Fukusumi M, Arashiro T, Arima Y, Matsui T, Shimada T, Kinoshita $\mathrm{H}$, et al. Dengue sentinel traveler surveillance: monthly and yearly notification trends among Japanese travelers, 20062014. PLoS Negl Trop Dis. 2016;10(8):e0004924.

63. Joob B, Wiwanitkit V. Clinical relevance of Zika symptoms in the context of a Zika Dengue epidemic. J Infect Public Health. 2020;13(1):158.

64. Vairo F, Haider N, Kock R, Ntoumi F, Ippolito G, Zumla A. Chikungunya. epidemiology, pathogenesis, clinical features, management, and prevention Infect Dis Clin North Am. 2019;33(4): 1003-25.

65. Hubschen JM, Bork SM, Brown KE, Mankertz A, Santibanez S, Ben Mamou M, et al. Challenges of measles and rubella laboratory diagnostic in the era of elimination. Clin Microbiol Infect. 2017;23(8):511-5.

66. Morey-Olive M, Espiau M, Mercadal-Hally M, Lera-Carballo E, Garcia-Patos V. Cutaneous manifestations in the current pandemic of coronavirus infection disease (COVID 2019). In: An Pediatr (Engl Ed); 2020.

67. Wong VK, Hitchcock W, Mason WH. Meningococcal infections in children: a review of 100 cases. Pediatr Infect Dis J. 1989;8(4):224 7.

68. Arend SM, Lavrijsen AP, Kuijken I, van der Plas RN, Kuijper EJ. Prospective controlled study of the diagnostic value of skin biopsy in patients with presumed meningococcal disease. Eur J Clin Microbiol Infect Dis. 2006;25(10):643-9. https://doi.org/10.1007/ s11882-020-00986-6

69. Jimenez-Cauhe J, Ortega-Quijano D, Carretero-Barrio I, SuarezValle A, Saceda-Corralo D. Moreno-Garcia Del Real C, et al. 
Erythema multiforme-like eruption in patients with COVID-19 infection: clinical and histological findings. Clin Exp Dermatol. 2020.

70. Frumholtz L, Laurent-Roussel S, Lipsker D, Terrier B. Cutaneous vasculitis: review on diagnosis and clinicopathologic correlations. Clin Rev Allergy Immunol. 2020.

71. Henry D, Ackerman M, Sancelme E, Finon A, Esteve E. Urticarial eruption in COVID-19 infection. J Eur Acad Dermatol Venereol. 2020;34(6):e244-e5.

72. Manalo IF, Smith MK, Cheeley J, Jacobs R. A dermatologic manifestation of COVID-19: transient livedo reticularis. J Am Acad Dermatol. 2020;83(2):700.

73. Piccolo V, Neri I, Filippeschi C, Oranges T, Argenziano G, Battarra VC, et al. Chilblain-like lesions during COVID-19 epidemic: a preliminary study on 63 patients. J Eur Acad Dermatol Venereol. 2020;34(7):e291-e3.

74. Gottlieb M, Long B. Dermatologic manifestations and complications of COVID-19. Am J Emerg Med. 2020;38(9):1715-21.

75.• Varga Z, Flammer AJ, Steiger P, Haberecker M, Andermatt R, Zinkernagel AS, et al. Endothelial cell infection and endotheliitis in COVID-19. Lancet. 2020;395(10234):1417-8. Biopsy-based demonstration of endothelial cell infection by SARS-CoV-2.

76. Ferrario CM, Jessup J, Chappell MC, Averill DB, Brosnihan KB, Tallant EA, et al. Effect of angiotensin-converting enzyme inhibition and angiotensin II receptor blockers on cardiac angiotensinconverting enzyme 2. Circulation. 2005;111(20):2605-10.
77. Roncati L, Ligabue G, Fabbiani L, Malagoli C, Gallo G, Lusenti B, et al. Type 3 hypersensitivity in COVID-19 vasculitis. Clin Immunol. 2020;217:108487.

78. Gianotti R, Zerbi P, Dodiuk-Gad RP. Clinical and histopathological study of skin dermatoses in patients affected by COVID-19 infection in the Northern part of Italy. J Dermatol Sci. 2020;98(2):141-3.

79. van Damme C, Berlingin E, Saussez S, Accaputo O. Acute urticaria with pyrexia as the first manifestations of a COVID-19 infection. $\mathrm{J}$ Eur Acad Dermatol Venereol. 2020;34(7):e300-e1.

80. Rodriguez-Jimenez P, Chicharro P, De Argila D, MunozHernandez P, Llamas-Velasco M. Urticaria-like lesions in COVID-19 patients are not really urticaria - a case with clinicopathological correlation. J Eur Acad Dermatol Venereol. 2020.

81. Cuker A, Peyvandi M. Coronavirus disease 2019 (COVID-19): hypercoagulability: Wolters: Kluwer; 2020. Available from: https://www.uptodate.com/contents/coronavirus-disease-2019covid-19-hypercoagulability

82. Tammaro A, Adebanjo GAR, Parisella FR, Pezzuto A, Rello J. Cutaneous manifestations in COVID-19: the experiences of Barcelona and Rome. J Eur Acad Dermatol Venereol. 2020;34(7):e306-e7.

Publisher's Note Springer Nature remains neutral with regard to jurisdictional claims in published maps and institutional affiliations.

\section{Affiliations}

\section{Désirée Larenas-Linnemann ${ }^{1,2}$ (1) $\cdot$ Jorge Luna-Pech ${ }^{3}$ (1) Elsy M. Navarrete-Rodríguez ${ }^{4}$ (D) $\cdot$ Noel Rodríguez-Pérez $^{5}$ (D) Alfredo Arias-Cruz ${ }^{6}$ (D) $\cdot$ María Virginia Blandón-Vijil ${ }^{7}$ (D) Blanca E. Del Rio-Navarro ${ }^{4}$ (D) $\cdot$ Alan Estrada-Cardona ${ }^{8}$ (D) Ernesto Onuma-Takane ${ }^{7}$ (D) Cesar Fireth Pozo-Beltrán ${ }^{9}$ (D) - Adriana María Valencia-Herrera ${ }^{10}$ (D) Francisco Ignacio Ortiz-Aldana ${ }^{11}$ (iD) Mirna Eréndira Toledo-Bahena ${ }^{10}$}

1 Médica Sur Fundación Clínica y Hospital, Mexico City, Mexico

2 Hospital Médica Sur, Torre 2, cons. Puente de piedra 150, T2-602 Toriello-Guerra; delegación Tlalpan, Mexico City, Mexico

3 Departamento de Disciplinas Filosóficas Metodoloógicas e Instrumentales, Universidad de Guadalajara, Guadalajara, Jalisco, Mexico

4 Servicio de Alergia e Inmunología Clínica, Hospital Infantil de Mexico Federico Gómez, Mexico City, Mexico

5 Consulta Privada, Universidad Autónoma de Tamaulipas, Matamoros, Tamaulipas, Mexico
6 Facultad de Medicina y Hospital Universitario Dr. José Eleuterio González, Universidad Autónoma de Nuevo León, Monterrey, Mexico

7 Consulta Privada, Hospital Médica Sur, Mexico City,, Mexico

8 Consulta Privada, Grupo COSTAMED, Playa del Carmen, Quintana Roo, Mexico

9 Subdirección de Enseñanza e Investigación, Hospital General de Especialidades Juan María Salvatierra, La Paz, Baja California Sur, Mexico

10 Servicio de Dermatología, Hospital Infantil de Mexico Federico Gómez, Mexico City, Mexico

11 ALERGO-ASMA de México, Irapuato, Guanajuato, Mexico 